This item was submitted to Loughborough's Research Repository by the author.

Items in Figshare are protected by copyright, with all rights reserved, unless otherwise indicated.

\title{
Willingness to pay for preferred seat selection on UK domestic flights
}

PLEASE CITE THE PUBLISHED VERSION

https://doi.org/10.1016/j.jairtraman.2018.04.018

PUBLISHER

(c) Elsevier

VERSION

AM (Accepted Manuscript)

PUBLISHER STATEMENT

This paper was accepted for publication in the journal Journal of Air Transport Management and the definitive published version is available at https://doi.org/10.1016/j.jairtraman.2018.04.018

\section{LICENCE}

CC BY-NC-ND 4.0

\section{REPOSITORY RECORD}

Rouncivell, Adam, Andrew Timmis, and Stephen Ison. 2019. "Willingness to Pay for Preferred Seat Selection on UK Domestic Flights". figshare. https://hdl.handle.net/2134/33066. 


\section{WILLINGNESS TO PAY FOR PREFERRED SEAT SELECTION ON UK} DOMESTIC FLIGHTS

by

\section{Adam Rouncivell}

Loughborough University

School of Architecture, Building and Civil Engineering, Loughborough, Leicestershire, LE11 2TU, UK

\section{Andrew J. Timmis (Corresponding Author)}

Loughborough University

School of Architecture, Building and Civil Engineering, Loughborough, Leicestershire, LE11 2TU, UK

Tel: +44 (0)1509 223416; Email: a.j.timmis@lboro.ac.uk

\section{Stephen G. Ison}

Loughborough University

School of Architecture, Building and Civil Engineering, Loughborough, Leicestershire, LE11 2TU, UK

Tel: +44 (0)1509 222605; Email: s.g.ison@lboro.ac.uk

\section{Please cite as:}

Rouncivell, A., Timmis, A., Ison, S.G. (2018) Willingness to pay for preferred seat selection on UK domestic flights. Journal of Air Transport Management, 70, 57-61. 


\title{
WILLINGNESS TO PAY FOR PREFERRED SEAT SELECTION ON UK DOMESTIC FLIGHTS
}

\begin{abstract}
This study employs a stated preference method to elicit and explore customer willingness to pay for airline ancillary products, specifically seat selection fees. Bivariate correlations are used to investigate linkages between passenger attributes and opinions with stated values for seat selection under a range of scenarios on UK domestic services.

The sensitivity of consumers to ticket fares, for both business and non-business travel, is found to be negatively correlated with the stated willingness to pay for their preferred seat. On the other hand, customer perceptions of airline reputation and convenience of flight times is positively correlated to willingness to pay for seat selection on non-business travel.

Additionally, the previous purchase of a seat selection product is strongly correlated to future willingness to pay for seat selection on both business and non-business travel. This is deemed to be the result of consumers being better able to value the benefits of their chosen seat from past experience.

This research expands on the current literature regarding the growing importance of airline ancillary revenue. The results provide an evidence base for the development of revenue management and the marketing of seat selection fees as an ancillary product.
\end{abstract}

Keywords: Willingness to pay, ancillary revenue, revenue management, airlines, stated preference, seat selection 


\section{INTRODUCTION}

In 2015, global airlines reported record annual profits in excess of \$35 billion (IATA, 2016). Increasing profitability was driven by falling input costs - fuel costs reduced from $33.1 \%$ (2012-2013) to $19.7 \%$ (2015) of operating costs-, robust passenger demand and increasing ancillary revenue. Despite record profitability, the global airline industry is notorious for being highly competitive with ticket fares close to marginal costs (Tretheway and Markhvida, 2014; O’Connell, 2011).

Ancillary revenues can be defined as "non-ticket revenues" (Wittmer et al., 2012). Broadly, they are categorised into two activities: "a la carte pricing"" and "purchasable supplementary services" (Holloway, 2008; Lovelock et al., 2009). A la carte pricing relates to the unbundling of product attributes that were formerly incorporated within the base fare (check-in baggage, in-flight hospitality and seat selection). Thus, aided by the growth of the internet and airline reservation systems, passengers can pick and choose which services they would like to utilise and allow airlines to offer competitive base fares. Supplementary services are a broad range of products and services that augment the core product [airline fare] by facilitating its use or enhancing its value and appeal (Lovelock et al., 2009). Examples of supplementary services offered by airlines include travel insurance, environmental products (carbon offsets) and airport car parking.

Ancillary revenue generated from non-core activity (ticket sales) has become an increasingly important and growing aspect of an airline's revenue stream for a variety of interconnected reasons: falling revenue yields on tickets sales, competition on base fares, 'unbundling' of fares by low cost carriers (LCCs) and online comparison websites (O’Connell, 2011). Globally, airline ancillary revenues have risen from $\$ 2.5$ billion in 2007 to $\$ 38.1$ billion in 2014 (IdeaWorksCompany, 2015). The introduction of new service fees can increase revenues but they may also reduce costs; an example being checked baggagefees reducing the volume of hold-luggage and thus associated handling fees borne by the airline (de Wit and Zuidberg, 2012). Waguespack and Rhoades (2014) identified the growing importance of baggage fees to US airlines analysing the increase in baggage fee revenue over the period 2007-2012. For example, in the examined five-year period Delta Airlines and US Airways increased revenue related to baggage fees by $796 \%$ and $1760 \%$ respectively.

Airlines continually seek to maximise the potential revenue from existing revenue streams and develop new sources from further unbundling - developing new products and services. These developments involve a complex balance between revenue management and customer satisfaction (Mumbower et al., 2015; Tuzovic et al., 2014). Setting the price for ancillary services involves balancing any potential revenue increase without adversely leading to a decline in basic ticket sales. A trend within the airline sector has been to disguise ancillary revenue increases within ever more complex products or offering these new ancillary products free to preferred or elite customers (Garrow et al., 2012). Despite the growing importance of ancillary revenue to the airline industry business model, academic research to date has been limited.

This paper involves a study of the UK domestic aviation market. Previous academic study has primarily focussed on the US domestic market (Scotti et al., 2016; Mumbower et al., 2015; Tuzovic et al., 2014; Garrow et al., 2012) or international travel: intra-European (Wittmer and Rowley, 2014) and South East Asian routes (Chang and Sun, 2012). The UK domestic market is characterised by short sector lengths, strong competition (between airlines and modes), a range of airline business models (LCCs and full-service network carriers (FSNCs)) and single-class all-economy (coach) seating. These features are characteristic of other European domestic markets.

The UK domestic aviation market represents a relatively small proportion of total UK aviation sector - only 8.5\% of total terminal passengers in 2016 (DfT, 2017). Between 2006 
and 2016 domestic aviation activity has fallen by $13 \%$ whilst overall UK aviation activity has grown $17.8 \%$. UK domestic air routes are diverse and range from feeder routes between UK regions and London Heathrow, inter- and intra-regional air routes and small public transport operations supported by public subsidy (Public Service Obligation).

The UK domestic aviation market is served by a range of airline operators and business models from the LCCs such as easyJet and Ryanair, subsidiary airlines of FSNCs British Airways and Aer Lingus through to the domestically focussed airlines Flybe and Loganair.

The customer's willingness to pay (WTP) for economy (coach) seat selection; the reasons being three-fold. Firstly, previous studies into WTP for seat selection have only examined WTP for the purchase of products with added passenger value ex-post their introduction e.g. premium coach (economy): extra leg-room, priority boarding, larger seat pitch (Hinnen et al., 2015; Mumbower et al., 2015) or, examined customer preferences and perceived fairness of ancillary services, e.g. the introduction of fees for previously free services (Waguespack and Rhoades, 2014; Wittmer and Rowley, 2014; O'Connell and Warnock-Smith, 2013). Secondly, passenger seat selection is ranked as the most important, and highly valued, of purchasable supplementary services for both long- and short-haul passengers (Wittmer and Rowley, 2014). Airline seating policies are a highly emotive topic and have recently been examined by the national aviation regulators (CAA, 2018).

\section{METHODOLOGY}

The Bristol Online Survey platform was used to create an online 14-question selfcompletion survey. The survey consisted of three parts. First, demographic data of the respondent was obtained and their past travel history. The second part consisted of six rating exercises where participants were asked to rate, on a linear 10-point scale $(1=$ not very important and $10=$ very important), the relative importance of factors in the ticket buying decision making process when comparing between two airlines: airline reputation, frequent flyer program (FFP), ticket price, price of ancillary products, flight times and convenience of connections. In the final section of the survey, respondents were asked in various scenarios to choose a preferred seat on an aircraft (with the aid of a generic A319 seat map) and state a monetary value for a seat they had chosen. Participants were asked to state their Willingness to Pay for a seat selection production unbundled from the air fare. The survey questions were pre-screened by two industry stakeholders with a working knowledge of airline booking and revenue management with the objective of assessing clarity, appropriateness and breadth.

Survey participants were recruited via a frequent flyer website focussed on both business and leisure travel. The website was chosen as a convenient vehicle to recruit passengers. The majority of respondents were not part of a Frequent Flyer Programme (see Table 1) and thus the results can be deemed generalisable amongst all passengers. A link to the questionnaire was posted on the message forum. The survey was posted on 23 December 2016 and was live for a period of 38 days. Participation in the study was entirely voluntary with participants receiving no reward. 800 respondents fully completed the survey within the time period. For the purpose of the data analysis, only those respondents who had previously flown a UK domestic route (excluding those to the Channel Isles and the Isle of Man), and who were likely to be interested in flying in the near future (on a UK domestic route within 5years) were included. Of those completed surveys, 622 (78\%) fulfilled the criteria.

Though 622 valid responses were collected in some instances, for example WTP for a preferred seat for business travel, respondents did not have to state a WTP if they did not travel by air for business purposes, thus reducing the sample size $n$. Non-business travel 
represents passengers who are travelling for the purposes of leisure/vacation travel or visiting family/relatives.

Respondent were asked to state their willingness to pay in British pounds (GBP). To allow comparison with previous studies the original monetary values have been converted to US Dollars ${ }^{1}$ where appropriate.

Ascertaining the representativeness of the collected sample is problematic since the demographic profile of UK domestic air travellers is not reported separately within the CAA Passenger Survey Report (2017). In Table 1 the age profile of UK passengers on domestic and international flights from the sample of airports reported in the latest passenger survey is given. The skew in the collected sample could be the result of the study's online recruitment. It is not however believed to invalidate the study findings.

TABLE 1 Summary of participant demographic data and travel history

\begin{tabular}{lcc}
\hline Attribute & $(\boldsymbol{\%})^{\mathrm{a}}$ & UK passengers \\
\hline Age (years) & - & \\
$18-29$ & 20.6 & 21.5 \\
$30-39$ & 36.8 & 22.2 \\
$40-49$ & 24.1 & 17.6 \\
$50-59$ & 13.7 & 18.6 \\
$60-69$ & 4.7 & 12.6 \\
$70+$ & 0.2 & 7.5 \\
\hline Previously paid a seat selection fee & - & - \\
Yes & 14.8 & - \\
No & 82.6 & - \\
Can't remember & 2.6 & - \\
\hline Reason for previous domestic travel & - & - \\
Business & 32.2 & - \\
Leisure/vacation & 44.4 & - \\
Visiting family/relatives & 23.6 & - \\
\hline Member of a frequent flyer program & - & - \\
Yes & 39.7 & - \\
No & 56.4 & - \\
Don't know/unsure & 3.8 & \\
\hline Total may not sum $t 0$ 100\% due to roundng & & - \\
\hline
\end{tabular}

${ }^{\text {a }}$ Total may not sum to $100 \%$ due to rounding

${ }^{\mathrm{b}}$ Population age distribution is based on CAA (2017) passenger survey data of UK passengers on domestic and international routes based on 8 airports: Birmingham, East Midlands, Gatwick, Heathrow, Liverpool, London City, Luton, Manchester and Stansted.

\section{RESULTS AND DISCUSSION Descriptive Statistics}

Mean willingness to pay for preferred seat selection for the two travel purposes are summarized in Table 2. A higher value of willingness to pay is observed when the purpose of a future flight is for business travel (£6.68; \$8.35) than for non-business travel ( $£ 5.56$; $\$ 6.95)$. Business travellers state a $20 \%$ premium to preferred seat selection fees over nonbusiness travellers. This could be explained by the fact that business travellers may be willing to pay more for seats at the front of the aircraft cabin to achieve time savings based on quicker boarding and disembarkation or business travellers are less price sensitive if travel expenses are being covered by employers. This would be in line with previous studies that have highlighted a higher value for travel time savings by business travellers compared to

$1 £ 1 \mathrm{GBP}=\$ 1.25 \underline{\mathrm{USD}}$ 
leisure travellers (Tsamboulas and Nikoleris, 2008; Pels et al., 2003). For both travel purposes, business and non-business, $50.1 \%$ and $60.4 \%$ respectively were willing to pay for preferred seat reservation. Excluding respondents who were not willing to pay, the aggregate sample mean increases for both travel scenarios. The previously observed business travel premium is maintained. Additionally, this confirms Chang and Sun's (2012) findings that business passengers display different characteristics in terms of the value they place on ancillary items.

By examining the specific subset of respondents who had previously paid a fee for seat selection a higher WTP was observed in both scenarios. Interestingly, the spread in valuations is lower than the aggregate samples; the implication being that passengers who have previously paid a seat selection fee are able to more consistently value the benefits of the seat they have selected.

It is interesting to note that despite $14.8 \%$ of respondents stating that they had paid for a seat selection product previously (see Table 1) a higher proportion of respondents were willing to pay for a seat selection product on a hypothetical future flight for business purposes (41\%) and leisure travel (59\%). This could be explained by the fact that a seat selection option has not been available on all UK domestic services or that the price of current products was greater than passenger WTP. This second point could be supported by the fact that participants who had previously purchased a seat selection product demonstrated a higher WTP.

TABLE 2 Willingness to Pay

\begin{tabular}{lccc}
\hline Hypothetical future flight & $\begin{array}{c}\text { Mean WTP } \\
(\mathfrak{f})\end{array}$ & $\begin{array}{c}\text { Standard } \\
\text { deviation }\end{array}$ & $\boldsymbol{n}$ \\
\hline Business trip & 6.68 & 8.40 & 449 \\
Business except those with WTP =0 & 11.76 & 8.02 & 255 \\
Non-business trip & 5.56 & 7.28 & 613 \\
Non-business except those with WTP & 9.21 & 7.35 & 370 \\
0 & & & \\
\hline Of those who have previously paid & & & \\
for seat selection & 9.22 & 4.47 & 59 \\
Business trip & 9.82 & 4.84 & 76 \\
Non-business trip & & & \\
\hline
\end{tabular}

Figure 1 shows the relative frequencies of willingness to pay for preferred seat selection fees for both future travel scenarios. In both instances the WTP distribution is positively skewed. What can't be observed is the grouping of WTP, for both business and non-business travel around multiples of 5 e.g. $£ 5, £ 10$. 


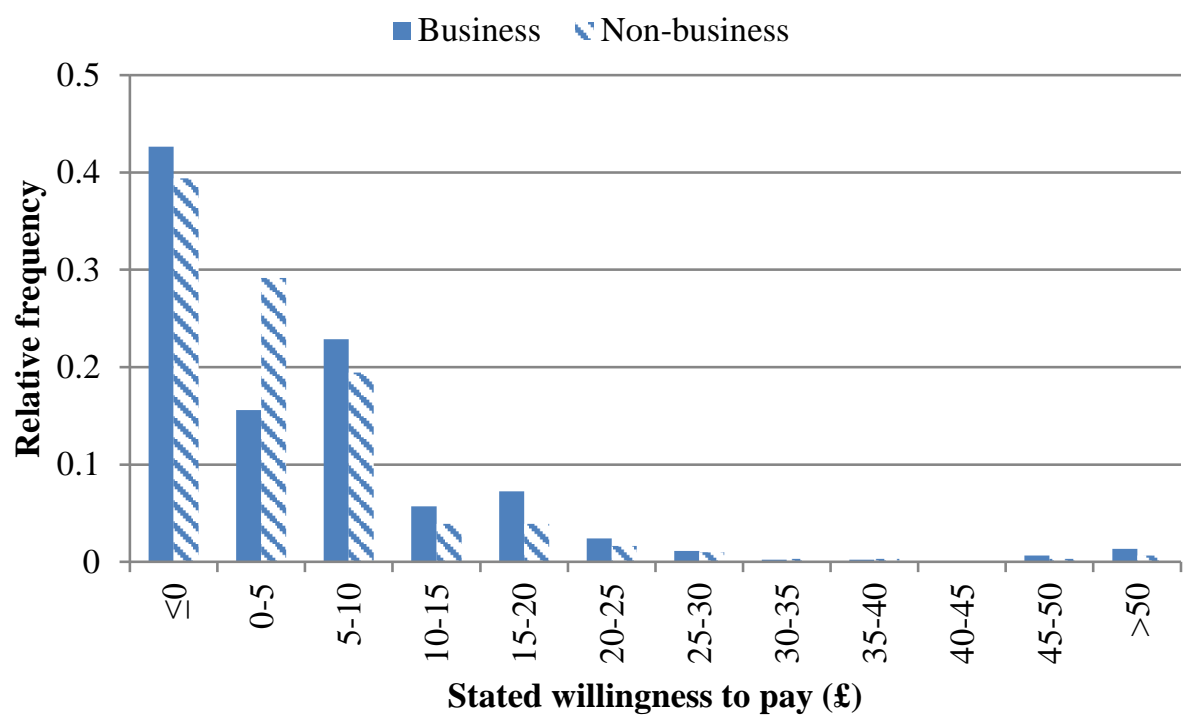

FIGURE 1 Willingness to Pay for preferred seat selection

We have demonstrated that the reason for travel (leisure or business purposes) affects WTP for a seat selection product. However, it should be noted that we make no distinction between route type e.g. regional airport to hub airport (trunk route) or inter-regional route. Previous studies into WTP for regional travel have identified this as a potential determinant of stated behaviour (Merkert and Beck, 2017).

Clearly there is only one 1A seat (the most popular selected seat) and a limited number of exit row seats. Respondents were asked to choose their preferred location in the cabin, with no choice of the exact seat. The majority of respondents preferred to sit in the front of the cabin (see Table 3). This is assumed to be due the ease of access for boarding and disembarking the aircraft. The WTP stated by respondents is less than that for their preferred individual seat (approximately £5).

The results also highlight the lack of value in the middle seat with no respondents choosing these seats. This result may be due to the lack of features of the middle seat: no window, and it lacks easy access to the aisle and overhead-bin space. Thus reinforcing the work of Weinstein and Keller (2016) and Mumbower et al (2015): there is no demand for the middle seat as a passenger's preferred seat. The implementation of passenger seat selection may give rise to a lack of consecutive seats for party bookings (of two or more travellers) to be seated together. Passengers are more likely (44\%) to pay for consecutive seats (anywhere on the aircraft) when the purpose of travel is for non-business purposes. This suggests that the purchase of a seat selection product is more complex than the valuation of extra legroom or proximity to the aircraft exit for ease of disembarkation. The purpose of travel influences what the passenger is willing to value. For non-business travel it may be that the ability to fly seated next to a travel companion is a valuable commodity.

TABLE 3 Preferred seat location

\begin{tabular}{|c|c|c|c|c|}
\hline & Location & Preference $(\%)^{a}$ & WTP $(\%)^{\mathbf{a}}$ & Mean WTP (£) \\
\hline \multirow{4}{*}{ : } & Front & 79.6 & 26.9 & 5.85 \\
\hline & Middle & 10.1 & 25.4 & 8.19 \\
\hline & Rear & 5.5 & 11.8 & 4.50 \\
\hline & No preference & 4.8 & N/A & N/A \\
\hline 皮 & Widow & 57.1 & 27.9 & 5.28 \\
\hline
\end{tabular}




\begin{tabular}{lccc} 
Middle & 0.0 & N/A & N/A \\
Aisle & 41.5 & 31.0 & 6.16 \\
No preference & 1.4 & N/A & N/A \\
\hline
\end{tabular}

${ }^{\text {a }}$ Total may not sum to $100 \%$ due to rounding

Clearly not all passengers can sit in their preferred seat. A significant proportion of passengers (approximately 25\%) demonstrate a WTP for a preferred seat position (windowaisle or front-back of cabin) if their preferred seat was unavailable. Thus, the information provided to customers in the process of purchasing ancillary products can influence their buying behaviour. Mumbower et al (2015) have previously demonstrated how seat availability maps can influence the customer decision making process in purchasing a premium coach seat product: a passenger is twice as likely to purchase a premium seat if the seat map is shown to be nearly full compared to a nearly empty plane.

When respondents rated the factors that influence their ticket purchase decision process (Table 4) ticket price (base fare) was the most important factor. This finding is consistent with numerous previous studies. Interestingly, the price of ancillary products (seat selection included) is the lowest ranked of all the factors considered. This may be due to the optionality of these additional products, or due to the opacity of the pricing structures; passengers may find it difficult to calculate a 'total price' (including ancillary fees) to compare between different airline operators. The increasing use of meta-search engines and online travel agents (e.g. Skyscanner.com) allow passengers to compare base fares, but it is only later in the booking process that ancillary products are made available.

TABLE 4 Rating of factors influencing the ticket purchasing decision

\begin{tabular}{lcc}
\hline Factor & Average rating (1-10) & Standard deviation \\
\hline Ticket Price & 8.36 & 1.95 \\
Flight times & 7.89 & 1.88 \\
Frequent flyer program & 7.31 & 2.55 \\
Airline reputation & 6.99 & 2.20 \\
Flight connections & 6.92 & 2.48 \\
Price of ancillary products & 6.00 & 2.59 \\
\hline
\end{tabular}

\section{Bivariate Correlations}

A Pearson bivariate correlation test was conducted for various surveyed variables and the stated willingness to pay for preferred seat selection on a hypothetical future UK domestic flight for the purpose of both business and non-business travel.

As previously highlighted, passengers rated base ticket price as the most important factor in the ticket decision purchasing process. It was hypothesised that this price sensitivity would be negatively correlated to a passenger's WTP for an ancillary product. For the purposes of business travel flight times and flight connections were predicted to be positively correlated to the WTP for a passenger's preferred seat. This hypothesis was made on the basis that a business traveller would be more time sensitive and valued ease of disembarkation/proximity to airplane exit.

Table 5 demonstrates that WTP for preferred seat selection is negatively correlated with the relative importance of base ticket price in the ticket decision purchasing process. For both business and non-business travel this was the strongest correlation calculated between the factors contained within the rating exercise and WTP. Flight times and flight connections were shown not to be significantly correlated to passenger WTP during flights for business purposes as hypothesized. 
When respondents were expressing WTP for seat selection, statistically significant positive correlation was found between seat selection fees and both airline reputation and flights times for non-business travel. However, in both cases the magnitude of the correlation was less than that observed for the ticket price. These relationships may reflect passengers perceiving highly regarded airlines as having a 'premium' seating, though it is difficult to understand what specific features of the chosen seats are valued by respondents.

Additionally, analysis was undertaken of the relationship between a future WTP seat selection fee (for business and non-business travel) for those passengers that reported to have previously paid a seat selection fee on a UK domestic flight. In both cases there was a very strong and statistically significant relationship. This finding may suggest those passengers who have previously purchased a seat selection product are better able to value the benefits of selecting their preferred seat due to past experience and knowledge of identified benefits. Furthermore, as highlighted in the previous section, this subset of respondents expressed a higher mean WTP than the survey sample as a whole (see Table 2).

TABLE 5 Bivariate correlation analysis

\begin{tabular}{|c|c|c|c|c|c|c|}
\hline \multirow[b]{2}{*}{ Variable } & \multicolumn{3}{|c|}{ Business } & \multicolumn{3}{|c|}{ Non-Business } \\
\hline & $\rho$ & $p$ & $\mathbf{n}$ & $\rho$ & $p$ & $\mathbf{n}$ \\
\hline Airline reputation & 0.058 & 0.216 & 449 & 0.088 & 0.030 & 613 \\
\hline $\begin{array}{l}\text { Frequent flyer } \\
\text { program }\end{array}$ & -0.028 & 0.560 & 449 & -0.005 & 0.901 & 613 \\
\hline Ticket price & -0.100 & 0.033 & 449 & -0.099 & 0.014 & 613 \\
\hline $\begin{array}{l}\text { Price of ancillary } \\
\text { products }\end{array}$ & 0.018 & 0.698 & 449 & 0.010 & 0.812 & 613 \\
\hline Flight times & 0.037 & 0.438 & 449 & 0.081 & 0.046 & 613 \\
\hline Flight connections & -0.032 & 0.496 & 449 & 0.072 & 0.077 & 613 \\
\hline $\begin{array}{l}\text { Previously paid a seat } \\
\text { fee }\end{array}$ & 0.477 & $<0.001$ & 59 & 0.657 & $<0.001$ & 76 \\
\hline
\end{tabular}

\section{Scenario Analysis}

A potential issue highlighted by earlier analysis of customer preferred seat selection is the issue of the middle seat - no passenger wants to sit in the middle seat as it lacks the benefits of the window or easy access to the aisle. If seats are allocated based on passenger preference there could potentially be few consecutive seats available for party bookings of 2 or more passengers. Additionally, previous analyses have focussed on individual passenger seat selection.

The survey consisted of two scenarios; respondents were asked to state their WTP for two adjacent seats (anywhere on the aircraft) for business and non-business travel. Respondents demonstrated a higher WTP for two adjacent seats if the nature of the flight was for business purposes (see Table 6). However, a higher proportion of respondents were willing to pay for two consecutive seats for non-business travel. This highlights the challenge faced by airlines in setting and maximizing ancillary revenue: balancing conversion with revenue yield. 
TABLE 6 Summary WTP data for two adjacent seat scenarios

\begin{tabular}{|c|c|c|}
\hline \multicolumn{3}{|c|}{ Scenario 1 - Travel purpose: Business $(n=622)$} \\
\hline Respondents WTP & - & $(\%)^{\mathrm{a}}$ \\
\hline Yes & 100 & 16.1 \\
\hline No & 347 & 55.6 \\
\hline Don't know & 12 & 1.9 \\
\hline $\begin{array}{l}\text { N/A - Don't fly for business } \\
\text { purposes }\end{array}$ & 163 & 26.2 \\
\hline WTP & Mean (£) & $\mathbf{n}^{\mathrm{c}}$ \\
\hline Total $^{\mathrm{b}}$ & 2.53 & 459 \\
\hline Except WTP $=£ 0$ & 11.62 & 100 \\
\hline \multicolumn{3}{|c|}{ Scenario 2 - Travel purpose: Non-business $(n=622)$} \\
\hline Respondents WTP & - & $(\%)^{a}$ \\
\hline Yes & 275 & 44.2 \\
\hline No & 294 & 47.3 \\
\hline Don't know & 53 & 8.5 \\
\hline WTP & Mean (£) & $\mathbf{n}$ \\
\hline Total $^{b}$ & 3.77 & 622 \\
\hline Except WTP $=£ 0$ & 8.52 & 275 \\
\hline
\end{tabular}

${ }^{\text {a }}$ Total may not sum to $100 \%$ due to rounding

b Assumes "No" and "Don't know" response WTP=£0

${ }^{\mathrm{c}}$ Excludes respondents who do not travel for business purposes

The demonstrated higher WTP for adjacent seats when the purpose of travel is for business has been statistically confirmed through performing a non-parametric Wilcoxon signed-rank test. The distribution of WTP is non-normal, as demonstrated under previous conditions (see Figure 1). The test was conducted on those respondents who stated a WTP for adjacent seats under both scenarios: business and non-business travel $(n=71)$. The Wilcoxon signed-rank test shows that passengers travelling for the purpose of business are willing to pay a statistically significant higher amount than travelling for non-business purposes $(\mathrm{Z}=-2.571, p=0.010)$.

The demonstrated WTP for two adjacent seats is less than the aggregate of two individual seats - thus demonstrating that the value of contiguous seats is not directly proportional to the party booking size. Therefore, airline revenue management should implement a seat selection product that accounts for the party booking size - an additional benefit of such a strategy would be that it could address the 'middle seat value gap' identified previously (see Table 3).

\section{CONCLUSIONS}

The aim of this study was to employ stated preference techniques to investigate passenger willingness to pay (WTP) for an ancillary product, namely preferred seat selection. The findings of this research demonstrate a clear willingness to pay for preferred seat selection on UK domestic air services, for both business and non-business travel with over $50 \%$ of passengers expressing a WTP $(50.1 \%$ for business travel and $60.4 \%$ for non-business travel). Despite a lower conversion of business passengers expressing a WTP, those that did expressed a value greater than non-business travellers.

It can be concluded that preferred seat selection is a viable revenue stream for airlines even with short sector lengths, as demonstrated by this study of UK domestic air routes where the average sector length is approximately $209.9 \mathrm{nmi}$ (DfT, 2015). The findings provide an 
evidence base for the development of revenue management strategies in the pricing, marketing and deployment of such products. It should also be noted that the unbundling of seat selection fees from the base fare should be seen not solely as a revenue management exercise, but may also increase passenger satisfaction levels by allowing passengers to sit where they feel most comfortable.

As the role of the ancillary products and services become a mature aspect of airline business models, both for LCCs and FSNCs, further work is needed to refine the revenue management models to maximize revenue yield and to explore the links with service quality. Overall, further research is required to investigate the relationship between WTP and sector length examining the price differential expressed between passenger groups to better understand the features and product attributes valued by identified passenger segments. Clearly, airlines offering differential pricing due to the purpose of travel are infeasible. However, differential presentation and marketing of ancillary products and their key features to different customer segments during the ticket purchase process could be developed. This differential approach is supported by one of the key findings of this study that business and leisure passengers express different WTP for ancillary products.

The research raises important questions for airline operators which require further investigation, most notably should all airlines be offering seat selection payment options, should they be offering different seat selection options on (mainly) leisure routes vs. (mainly) tourist routes and in a UK context since many of the domestic flights are feeder flights with passengers connecting through hub airports, should, if at all possible, the seat selection for the domestic flight be tied into the seat selection for the onward flight? 


\section{REFERENCES}

Chang, L., Sun, P. (2012) Stated choice analysis of willingness to pay for low cost carrier services. Journal of Air Transport Management, 20, 15-17.

Civil Aviation Authority (2018) Civil Aviation Authority launches review of airlines' allocated seating policies. [online] Available at: < https://www.caa.co.uk/News/CivilAviation-Authority-launches-review-of-airlines--allocated-seating-policies/ > [Accessed 06 March 2018].

Civil Aviation Authority (2017) CAA Passenger Survey Report 2016. [pdf] Civil Aviation Authority. Available at: <

https://www.caa.co.uk/uploadedFiles/CAA/Content/Standard_Content/Data_and_anal ysis/Datasets/Passenger_survey/CAA\%20Passenger\%20Survey\%20Report\%202016. pdf $>$

De Wit, J.G., Zuidberg, J. (2012) The growth limits of the low cost carrier model. Journal of Air Transport Management, 21, 27-23.

Department for Transport (2015) Activity by UK airlines, July 31, 2015. https://www.gov.uk/government/statistical-data-sets/avi02-employment-and-flightdestinations. Accessed July 16, 2016.

Garrow, L.A., Hotle, S., Mumbower, S. (2012) Assessment of product debundling trends in the US airline industry: Customer service and policy implications. Transportation Research Part A: Policy and Practice, 46 (2), 255-268.

Hinnen, G., Hille, S.L., Wittmer, A. (2015) Willingness to pay for green products in air travel: Ready for take-off?. Business Strategy and the Environment. Advance online publication, DOI: 10.1002/bse.1909

Holloway, S. (2008) Straight and Level: Practical Airlines Economics, Third Ed. Ashgate Publishing Limited, Aldershot, UK.

IATA (2016) Annual Review 2016. http://www.iata.org/publications/Documents/iata-annualreview-2016.pdf. Accessed July 07, 2016.

IdeaWorksCompany (2015). The CarTrawler Yearbook of Ancillary Revenue.

Lovelock, C.H., Writz, J., Chew, P. (2009). Essentials of Services Marketing. Prentice Hall, Singapore.

Merkert, R., Beck, M. (2017) Value of travel time savings and willingness to pay for regional aviation. Transportation Research Part A: Policy and Practice, 96, 29-42.

Mumbower, S., Garrow, L.A., Newman, J.P. (2015) Investigating airline customers' premium coach seat purchases and implications for optimal pricing strategies. Transportation Research Part A: Policy and Practice, 73, 53-69.

O'Connell, J.F. (2011) Ancillary revenues: the new trend in strategic airline marketing. In: O'Connell, J.F., Williams, G. (eds) Air Transport in the $21^{\text {st }}$ Century: key strategic developments. Ashgate, Farnham, UK.

O'Connell, J.F., Warnock-Smith, D.W (2013) An investigation into traveller preferences and acceptance of airline ancillary revenues. Journal of Air Transport Management, 33, 12-21.

Pels, E., Nijkamp, P., Rietveld, P. (2003) Access to and competition between airports: a case study for the San Francisco Bay area. Transportation Research Part A: Policy and Practice, 37(1), 71-83

Scotti, D., Dresner, M., Martini, G. (2016) Baggage fees, operational performance and customer satisfaction in the US air transport industry. Journal of Air Transport Management, 55, 139-146.

Tretheway, M.W., Markhvida, K. (2014) The aviation value chain: Economic returns and policy issues. Journal of Air Transport Management, 41, 3-16. 
Tsamboulas, D.A., A. Nikoleris. Passengers' willingness to pay for airport ground access time savings. Transportation Research Part A: Policy and Practice, Vol. 42, No. 10, 2008, pp. 1274-1282.

Tuzovic, S., Simpson, M.C., Kuppelwieser, V.G., Finsterwalder, J. (2014) From 'free' to 'fee': Acceptability of airline ancillary fees and the effects on customer behaviour. Journal of Retailing and Consumer Services, 21(2), 98-107.

Waguespack, B.P., Rhoades, D.L. (2014) Twenty five years of measuring airline service quality or why is airline service quality only good when times are bad?. Research in Transportation Business \& Management, 10, 33-39.

Weinstein, D., Keller, J. (2016) Findings from RSG's bi-annual air passenger study.

Presented at the Choice-based Revenue Management Conference, Georgia Institute of Technology, Atlanta, GA.

http://garrowlab.ce.gatech.edu/sites/default/files/files/rsg_0.pdf . Accessed July 13, 2016.

Wittmer, A., Gerber, A., Boksberger, P. (2012) The future of ancillary service fees in air travel - an exploratory investigation of budget air travellers. International Journal of Aviation Management, 1(4), 231-241.

Wittmer, A., Rowley, E. (2014). Customer value of purchasable supplementary services: The case of a European full network carrier's economy class. Journal of Air Transport Management, 34, 2014, 17-23 